\title{
Morfologia dos músculos do ombro do Sapajus apella (Primates: Cebidae)
}

\author{
Mariana Oliveira Lima ${ }^{1 *}$ \\ Lucélia Gonçalves Vieira ${ }^{1}$ \\ Priscilla Rosa Queiroz Ribeiro ${ }^{1}$ \\ Gilmar da Cunha Sousa ${ }^{1}$ \\ Zenon Silva $^{2}$ \\ Daniela Cristina de Oliveira Silva ${ }^{1}$ \\ Roseâmely Angélica de Carvalho Barros ${ }^{2}$

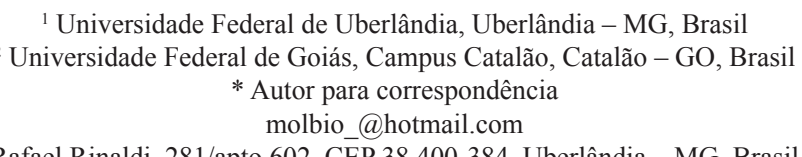

Submetido em 19/09/2012

Aceito para publicação em 10/12/2012

\section{Resumo}

O estudo de primatas não humanos tem sido de grande interesse, devido às semelhanças com a espécie humana. Várias espécies animais, principalmente de primatas, têm sido usadas em pesquisas médicas e biológicas. O Sapajus apella é uma espécie de ocorrência comum e abundante na Região Sudeste. O objetivo deste trabalho foi estudar os músculos estabilizadores do ombro do macaco-prego e compará-los com os do ser humano, com a finalidade de fornecer subsídios para interpretações anátomo-funcionais que auxiliarão em futuros trabalhos de anatomia comparada. Foram utilizados quatro exemplares de $S$. apella provenientes do Laboratório de Anatomia Humana da Universidade Federal de Uberlândia. Os espécimes foram preparados por meio de dissecação dos músculos estabilizadores do ombro e preservados em solução de formaldeído. Observou-se que os músculos estabilizadores do ombro do $S$. apella apresentam semelhanças morfológicas, em relação à origem e inserção, com aqueles que se encontram nos seres humanos, bem como em outros primatas.

Palavras-chave: Anatomia comparada; Macaco-prego; Músculo subescapular

\section{Abstract}

Morphology of the shoulder muscles in Sapajus apella (Primates: Cebidae). The study of nonhuman primates has been very important, due to the similarities with the human species. Many animal species, especially primates, have been used in medical and biological researches. Sapajus apella is a species with usual and abundant incidence in the Southeastern Region. This paper aimed to study the stabilizing muscles of the shoulder in the tufted capuchin monkey and compare them to those in human beings, with the purpose of providing information to anatomical and functional interpretations which will be useful for further studies 
on comparative anatomy. Four specimens of $S$. apella from the Human Anatomy Laboratory of Universidade Federal de Uberlandia were used. The specimens were prepared through dissection of the stabilizing muscles of the shoulder and preserved in formaldehyde solution. It was observed that the shoulder stabilizing muscles of the $S$. apella present morphological similarities, regarding origin and branching, with those found in human beings, as well as in other primates.

Key words: Comparative anatomy; Subscapular muscle; Tufted capuchin monkey

\section{Introdução}

Os primatas não humanos têm se constituído um importante grupo dentre os animais submetidos a vários estudos, o que se reveste de suma importância até para o entendimento de sua própria evolução, somandose ao fato de que o conhecimento pormenorizado de sua anatomia pode representar fator importante para preservação e proteção. Nos últimos 30 anos, o estudo desses primatas tem recebido grande atenção, talvez devido à sua semelhança anatômica com a espécie humana (AURICCHIO, 1995).

A utilização do Sapajus apella, em estudos anatômicos, cresceu muito nos últimos anos, em razão do seu pequeno porte, fácil manuseio e relativa facilidade de se reproduzirem em cativeiro (BARROS, 2002). Esta espécie de primata se caracteriza por apresentar tamanho médio, podendo chegar a cinco ou seis quilos, pêlos pretos ou de cor castanha de vários matizes, sendo mais comum o castanho escuro. Sato e Izar (1999) afirmam que os macacos desta espécie são curiosos, inquietos e apresentam um tufo de pêlos no alto da cabeça que lembra um topete. Vivem em grupos de até 30 indivíduos em média, e espalham-se pela América do Sul, da Colômbia à Argentina. No Brasil, ocupam ambientes tão variados quanto a floresta Amazônica, o cerrado, a caatinga e a Mata Atlântica (SATO; IZAR, 1999). São frequentes na região sudeste e não estão ameaçados de extinção (BARROS, 2002).

Os hábitats onde se localizam vêm sendo progressivamente destruídos (AURICCHIO, 1995), outro motivo que estimula a pesquisa dessa espécie, principalmente para sua preservação e reprodução em cativeiro.

Vários trabalhos que abordam aspectos anatômicos do macaco $S$. apella estão disponíveis na literatura, como, por exemplo, descrição dos plexos lombar, sacral e coccígeno
(BARROS, 2002); músculos da região glútea (DIAS NETO, 2003); origem do plexo braquial (RIBEIRO et al., 2005) e plexo lombar (BARROS et al., 2003); descrição do músculo dorsoepitroclear (AVERSI-FERREIRA et al., 2005a); anatomia descritiva e topográfica do músculo digástrico (FERREIRA et al., 2005); estudo anatômico de músculos profundos do antebraço (AVERSI-FERREIRA et al., 2005b) e dos músculos flexores superficiais do antebraço (AVERSI-FERREIRA et al., 2006). No entanto, pesquisas envolvendo a anatomia funcional dos músculos que estabilizam o ombro do $S$. apella ainda não existem na literatura.

Os músculos supraespinhal, infraespinhal, redondo menor e subescapular constituem os músculos estabilizadores do ombro. Estes músculos têm como principal ação, manter a cabeça do úmero na cavidade glenóide da escápula, assegurando assim a principal estabilidade da articulação do ombro e reforçando esta articulação em todas as partes, exceto embaixo (MOORE, 2001).

O conhecimento morfológico desse segmento acrescentará informações aos dados já existentes na literatura especializada, poderá auxiliar na preservação da espécie, no entendimento da evolução e é fundamental para futuras pesquisas em anatomia, fisiologia, toxicologia e farmacologia, devido, também à sua proximidade filogenética com o homem.

O objetivo desta pesquisa consistiu em analisar as variações das origens e inserções e provável ação dos músculos estabilizadores do ombro no macaco S. apella e compará-los com humanos e outras espécies de primatas.

\section{Material e Métodos}

Para o desenvolvimento deste trabalho, utilizaram-se quatro espécimes de $S$. apella, sendo dois 
machos e duas fêmeas adultos pertencentes ao acervo do Laboratório de Anatomia da Universidade Federal de Uberlândia, cedidos pelo IBAMA - MG (Instituto Brasileiro do Meio Ambiente e Recursos Renováveis).

O material anatômico estudado foi fixado em solução aquosa de formaldeído a 3,7\%, e posteriormente conservado imerso em solução de igual concentração.

A visualização da musculatura destes animais foi possível pelo método de dissecação da área proposta em ambos os antímeros, segundo as técnicas e procedimentos usuais em anatomia proposta por Rodrigues (2005). As estruturas de interesse foram cuidadosamente limpas e isoladas, o que permitiu evidenciar a origem, inserção e trajeto das fibras musculares dos músculos do ombro. Após este processo, os dados foram catalogados e comparados com a literatura disponível acerca destas estruturas em humanos e outras espécies de primatas.

Quando necessário foi utilizada uma lupa, com aumento de até $10 \mathrm{X}$.

A terminologia adotada para descrição das estruturas anatômicas de interesse foi de acordo com International Committee on Veterinary Gross Anatomical Nomenclature (2012).

A fotodocumentação dos resultados foi feita utilizando-se uma câmera digital Canon Power Shot A70, com resolução de 3.2 megapixels.

\section{Resultados e Discussão}

Quatro músculos do ombro atuam na estabilização do úmero no $S$. apella. Este grupo é formado pelos músculos supraespinhal, infraespinhal, redondo menor e subescapular. As inserções desses músculos formam um conjunto musculoaponeurótico em torno da articulação do ombro, à qual conferem estabilidade e realizam rotação do úmero. Cada músculo que compõe a musculatura estabilizadora do ombro é aqui descrito e discutido separadamente em relação à sua forma, localização, origem, inserção, inervação e provável ação.

\section{Músculo subescapular}

O músculo subescapular do $S$. apella é um grande e espesso músculo que ocupa toda a fossa subescapular. Observação semelhante foi relatada por Swindler e Wood (1982) em Baboon e Chimpanzee. No S. apella, este músculo mostra aspecto fascicular, classificando-o como um músculo multipenado, com aspecto de leque. Possui ainda, uma borda caudal intimamente relacionada ao músculo redondo maior. Na metade medial ambos os músculos estão fundidos.

No que diz respeito a fixação medial (origem) desse músculo, no $S$. apella e em outras espécies de macacos (SCHÖN, 1968; SWINDLER; WOOD, 1982), bem como no homem (TESTUT; LATARJET, 1979), ocorre ao longo de toda a extensão da borda cranial, borda medial e ângulo caudal da escápula. Ele também se encontra fixado na superfície da escápula ao longo de toda a fossa subescapular, onde várias cristas ósseas se fazem presentes e servem para fixação do músculo. Especificamente o fascículo cranial deste músculo, no $S$. apella, cuja origem ocorre na borda superior da escápula cruza sob o processo coracóide em direção à articulação escápulo-umeral, enquanto o fascículo mais caudal tem sua fixação de origem na borda inferior da escápula, junto com fibras do músculo redondo maior até o ângulo inferior da escápula.

No geral, todos os fascículos deste músculo em $S$. apella convergem em direção ao processo coracóide da escápula para se inserir no tubérculo menor do úmero, por meio de um tendão achatado que se apresenta firmemente conectado à cápsula articular. Inserção semelhante foi visto em Alouatta, Ateles, Brachyteles, Lagothrix, em outras espécies de Cebus (SCHÖN, 1968) e também no homem (MOORE, 2001). Este autor aponta o subescapular como um potente músculo, devido à sua estrutura muscular, o mesmo pode se aplicar ao $S$. apella, além do mais nesta espécie em estudo as fibras mais caudais inserem-se por um tendão muito curto, como se fixassem diretamente no osso, imediatamente distal ao tubérculo menor.

Ao observar a Figura 1, nota-se que os fascículos do músculo subescapular em $S$. apella podem estar tão nitidamente separados que se aparentam como músculos 
FIGURA 1: Músculo subescapular do Sapajus apella em vista ventral. aca, ângulo caudal da escápula; acr, ângulo cranial da escápula; bcr, borda cranial da escápula; $\mathbf{C}$, borda medial da escápula; fm, fascículos musculares; i, inserção do músculo subescapular; mrma, músculo redondo maior; msb, músculo subescapular; tm, tubérculo menor do úmero.

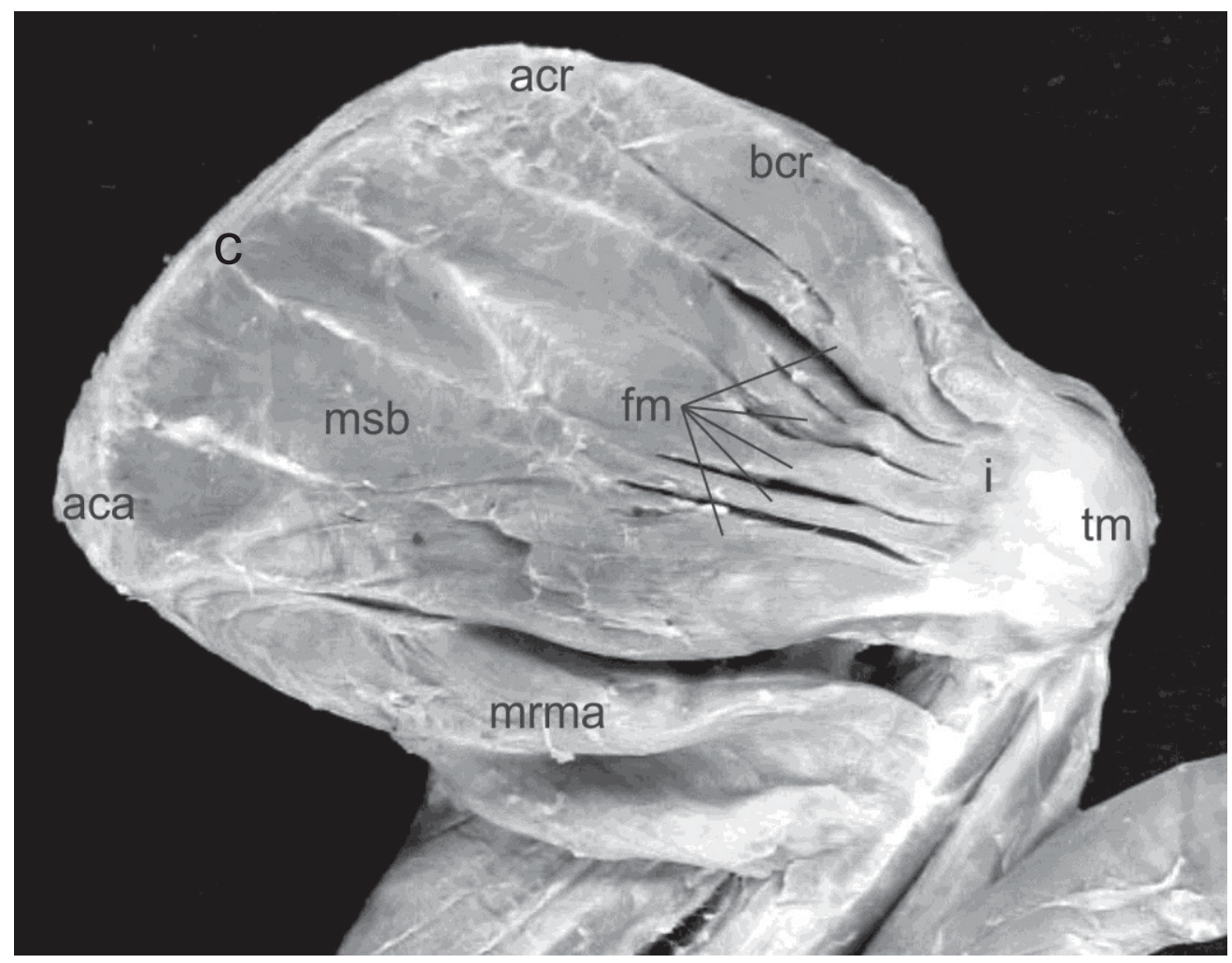

individuais. Desta maneira, podem-se distinguir grupos de fascículos médios que representa o músculo subescapular em si, e os fascículos cranial e caudal que se constituem em músculos acessórios.

A inervação do músculo subescapular do $S$. apella provém de dois ou três nervos subescapulares, e a julgar pela sua disposição o músculo se constitui em um rotador medial do úmero.

\section{Músculo supraespinhal}

O músculo supraespinhal do $S$. apella é uma volumosa massa muscular que ocupa a fossa supraespinhal. Dado esse que é confirmado por Schön (1968) e por Testut e Latarjet (1979) e Moore (2001), ao citar que o músculo supraespinhal é tão largo quanto à fossa supraespinhal da qual ele se origina.

Suas fibras musculares, no $S$. apella, exibem uma fixação de origem ao longo dos $2 / 3$ mediais da espinha da escápula, ângulo superior e borda cranial da escápula em sua metade medial, mas também está fixado em toda superfície da fossa supraespinhal, inclusive na face cranial da espinha da escápula, também observados em humanos (TESTUT; LATARJET, 1979; MOORE, 2001) e em outros primatas (SCHÖN, 1968; SWINDLER; WOOD, 1982).

As fibras deste músculo convergem em direção à articulação do ombro para formarem um forte tendão, através do qual vão se fixar na extremidade proximal do tubérculo maior do úmero, assim como secundariamente na superfície da cápsula articular do ombro (Figura 2).

Devido a sua estrutura, bem como origem e inserção no $S$. apella, este músculo é principalmente um flexor do braço, secundariamente um rotador lateral do úmero, e constitui-se, além disso, em um importante ligamento ativo da articulação do ombro, o qual mantém justaposta a cabeça do úmero contra a superfície glenoidal. Função semelhante foi constatada 
FIGURA 2: Região escapular do Sapajus apella em vista dorsal. ee, espinha da escápula; mde, músculo deltóide; mle, músculo levantador da escápula; mrma, músculo redondo maior; msp, músculo supraespinhal; mtr, parte torácica do músculo trapézio; smin, parte superficial do músculo infraespinhal.

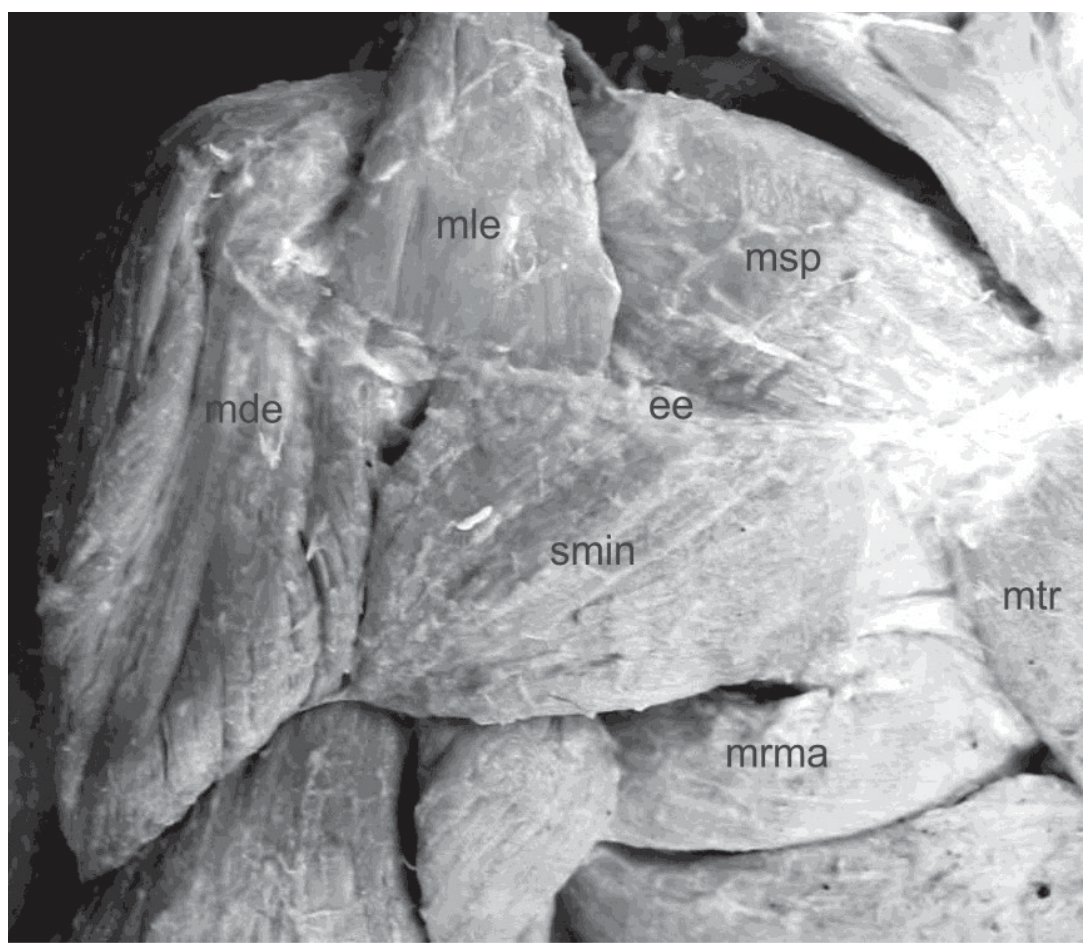

no homem por Testut e Latarjet (1979) e Williams et al. (1995), e em outros primatas por Schön (1968) e Swindler e Wood (1982).

Moore (2001) descreve, para humanos, o músculo supraespinhal como localizado na fossa supraespinhal, sob o músculo trapézio e o arco coraco-acromial; seu tendão é recoberto pelo músculo deltóide, e sua origem se dá na fossa supraespinhal da escápula e sua inserção na face superior do tubérculo maior do úmero. No $S$. apella, o músculo supraespinhal encontra-se totalmente encoberto pelo músculo trapézio, sua inervação provém do nervo supra-escapular, através de vários filamentos neurais.

\section{Músculo infraespinhal}

É o maior e mais volumoso músculo estabilizador do ombro do $S$. apella. Está subdividido em partes profunda e superficial.

A parte superficial mostra aspecto quadrilátero, e se avoluma entre o trapézio cranialmente, o deltóide lateralmente e as cabeças lateral e longa do tríceps braquial. Esta parte do músculo infraespinhal encobre totalmente o músculo redondo menor. $\mathrm{O}$ mesmo foi observado nas descrições de Schön (1968) ao afirmar que esse músculo possui uma forma triangular em correspondência com a fossa infraespinhal, a qual é por ele inteiramente ocupada. No S. apella, a parte profunda contribui no preenchimento da fossa infraespinhal. Williams et al. (1995) relataram que o músculo infraespinhal ocupa nos humanos, a maior parte da fossa infraespinhal. Estes autores não descreveram subdivisões para este músculo (Figura 3).

No $S$. apella, os fascículos caudais têm origem na parte média da borda medial e também na superfície escapular, convergem lateral e cranialmente. As fibras dos fascículos craniais exibem origem ao longo da metade cranial da borda medial da escápula; $2 / 3$ mediais da espinha da escápula, e maior parte da superfície escapular da fossa infraespinhal, inclusive a face distal da espinha da escápula. 
FIGURA 3: Ombro do Sapajus apella em vista dorsal. aca, ângulo caudal da escápula; acm, acrômio; acr, ângulo cranial da escápula; bcr, borda cranial da escápula; bme, borda medial da escápula; ee, espinha da escápula; i, inserção do músculo supraespinhal; min, músculo infraespinhal; mrma, músculo redondo maior; mrme, músculo redondo menor; msp, músculo supraespinhal; mtr, músculo tríceps braquial.

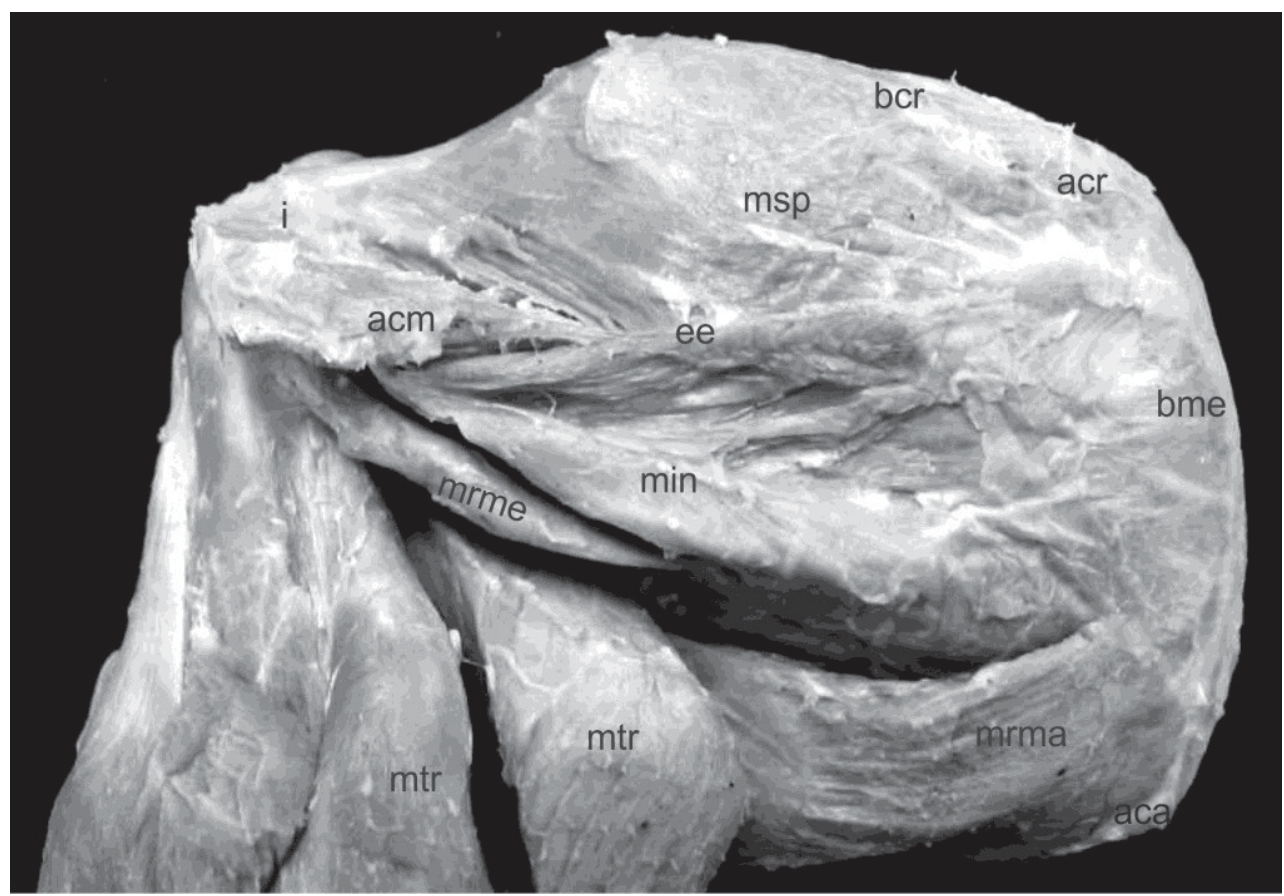

As numerosas fibras que formam a parte superficial do músculo infraespinhal exibem origem na fáscia aponeurótica que as recobre. As fibras de ambas as partes deste músculo convergem em um tendão central, que por sua vez se insere na parte média do tubérculo maior do úmero, e, secundariamente, na cápsula articular do ombro.

A inervação deste músculo provém do nervo supraescapular, ramo do plexo braquial, o que se confirma nas observações de Swindler e Wood (1982). Face à sua forma e posição, o músculo infraespinhal é fundamentalmente um rotador lateral do úmero, mas é também um ligamento ativo da articulação do ombro de $S$. apella, o que também se observa em humanos.

\section{Músculo redondo menor}

O músculo redondo menor do $S$. apella é um pequeno músculo cilíndrico, que constitui o menor dos músculos estabilizadores do ombro. Tal observação foi também constatada por Tortora (2007). Para Schön (1968), em macacos este é, de fato, um músculo muito pequeno quando comparado àqueles que o circundam.
No $S$. apella, possui uma ampla origem ao longo da superfície dorsal da escápula, muito próxima à borda distal da mesma, junto à origem da cabeça longa do músculo tríceps braquial. Muitas de suas fibras craniais estão fundidas com fibras do músculo infraespinhal, sendo que em alguns casos aparece totalmente fundido com esse músculo, ao menos em seus $2 / 3$ mediais.

Todas estas informações estão em conformidade com Swindlere Wood (1982), ao citarem o redondo menor como um músculo cilíndrico que se encontra geralmente associado com a porção caudal do infraespinhal, e sendo na maioria dos primatas difícil de individualizar esses dois músculos. Tortora (2007) relatou que no homem este músculo é frequentemente inseparável do infraespinhal.

A partir de suas fixações de origem, as fibras do músculo redondo menor dirigem-se oblíqua, cranial e lateralmente para inserir na faceta distal do tubérculo maior do úmero, sendo que os fascículos distais se fixam na linha distal ao mesmo tubérculo. Em humanos, a origem deste músculo está situada na parte superior da borda lateral da escápula e sua inserção encontra-se 
localizada na face inferior do tubérculo maior do úmero (SNELL, 1984). Este autor, ainda complementa que os tendões dos quatro músculos que formam os músculos estabilizadores do ombro, em primatas humanos, fundem-se com a porção lateral da cápsula articular da articulação do ombro, reforçando-a, protegendo a articulação e lhe dando estabilidade, mantendo a cabeça relativamente grande do úmero na pequena e rasa cavidade glenóide da escápula durante os movimentos do braço.

O músculo redondo menor no $S$. apella recebe inervação proveniente do nervo axilar. Em S. apella esse músculo possui a mesma ação do infraespinhal, como foi descrito por Schön (1968), imprimindo rotação lateral ao úmero e mantendo estável a articulação do ombro, como um ligamento ativo.

A partir dos resultados foi possível concluir que o ombro do $S$. apella é, em todos os aspectos, semelhante ao do homem.

\section{Referências}

AURICCHIO, P. Primatas do Brasil. São Paulo: Terra Brasilis, $1995.168 \mathrm{p}$.

AVERSI-FERREIRA, T. A.; AVERSI-FERREIRA, R. A. G. M. F.; SILVA, Z.; GOUVÊA-E-SILVA, L. F.; PENHA-SILVA, N Estudo anatômico dos músculos profundos do antebraço de Cebus apella (Linnaeus, 1766). Acta Scientiarum. Biological Sciences, Maringá, v. 27, n. 3, p. 297-301, 2005a.

AVERSI-FERREIRA, T. A.; LIMA-E-SILVA, M. S.; PEREIRADE-PAULA，J.; GOUVÊA-E-SILVA， L. F.; PENHA-SILVA, N. Anatomia comparativa dos nervos do braço de Cebus apella. Descrição do músculo dorsopitroclear. Acta Scientiarum. Biological Sciences, Maringá, v. 27, n. 3, p. 291-296, 2005 b.

AVERSI-FERREIRA, T. A.; VIEIRA, L. G.; PIRES, R. M.; SILVA, Z.; PENHA-SILVA, N. Estudo anatômico dos músculos flexores superficiais do antebraço no macaco Cebus apella. Bioscience Journal, Uberlândia, v. 22, n. 1, p. 139-144, 2006.

BARROS, R. A. C. Estudo anatômico dos plexos lombar, sacral e coccígeno do macaco Cebus apella - origem, composição e nervos resultantes. 2002. 146 f. Dissertação (Mestrado em Anatomia dos Animais Domésticos) - Universidade de São Paulo, São Paulo. 2002.
BARROS, R. A. C.; PRADA, I. L. S.; SILVA, Z.; RIBEIRO, A. R. SILVA, D. C. O. Constituição do plexo lombar do macaco Cebus apella. Brazilian Journal of Veterinary Research and Animal Science, São Paulo, v. 40, n. 5, p. 373-381, 2003.

DIAS NETO, O. C. Estudo anatômico dos músculos da região glútea do macaco Cebus apella. 2003. 58 f. Monografia (Graduação em Ciências Biológicas) - Universidade Federal de Uberlândia, Uberlândia. 2003.

FERREIRA, J. R.; PINTO-JÚNIOR, N.; KAJITA, D. D.; CIRQUEIRA, S.; NOGUEIRA, D.J. Estudo da anatomia descritiva e topográfica do músculo digástrico em primatas (Cebus apella, Linnaeus, 1766). Brazilian Journal of Veterinary Research and Animal Science, São Paulo, v. 42, n. 2, p. 113-121, 2005.

INTERNATIONAL COMMITTEE ON VETERINARY GROSS ANATOMICAL NOMENCLATURE. Nomina anatomica veterinária. 5. ed. (rev.) Knoxville: World Association on Veterinary Anatomist, 2012. 177 p.

MOORE, K. L. Anatomia orientada para clínica. 4. ed. Rio de Janeiro: Guanabara Koogan, 2001. 1021 p.

RIBEIRO, A. R.; PRADA, I. L. S.; SILVA, Z.; BARROS, R. A. C.; SILVA, D. C. O. Origem do plexo braquial do macaco Cebus apella. Brazilian Journal of Veterinary Research and Animal Science, São Paulo, v. 42, n. 2, p. 143-149, 2005.

RODRIGUES, H. Técnicas anatômicas. 3 ed. Vitória: Edson Arte, 2005. 229 p.

SATO, T.; IZAR, P. Comportamento animal: o mais inteligente das Américas. Revista da FAPESP: Ciência, n. 49, 1999. Disponível em: <http://www.revistapesquisa.fapesp.br:2222/transform.php?xml $=4 / 0 / 20011004 / 19991249 / \mathrm{pt} / \mathrm{SEC1} 4 . x m 1 \& x s 1 / \mathrm{pt} /$ article.xsl\&tran $\mathrm{sf}=$ normal\&id=SEC1_4\&lang=pt\&issue $=19991249>$. Acesso em: 15 mar. 2012.

SCHÖN, M. A. The muscular system of the Red Howling Monkey. Washington: Smithsonian Institution-Museum of Natural History, 1968. 185 p.

SNELL, R. S. Anatomia. 2. ed. Rio de Janeiro: Medsi, 1984. 802 p. SWINDLER, D. R.; WOOD, C. D. An atlas of primate gross anatomy: baboon, chimpanzee and man. Florida: Robert E. Krieger Publishing Company, 1982. 392 p.

TESTUT, L; LATARJET, A. Anatomia humana. v. 1. Barcelona: Salvat, 1979. $1142 \mathrm{p}$.

TORTORA, G. J. Princípios de anatomia humana. 10 ed. Rio de Janeiro: Guanabara Koogan, 2007. 1056 p.

WILLIAMS, P.; WARWICK, R.; DYSON, M.; BANNISTER, L. H. Gray anatomia. v. 1. 37. ed. Rio de Janeiro: Guanabara Koogan, 1995. 1489 p. 